\title{
Service Quality at a South African University: An Exploratory Study
}

\section{Christopher May}

School of Economic Sciences, North-West University, Vanderbijlpark, South Africa

Christopher.May@nwu.ac.za

Peet Viljoen

School of Economic Sciences, North-West University, Vanderbijlpark, South Africa

Peet.Viljoen.@nwu.ac.za

\section{Doi:10.5901/mjss.2014.v5n20p882}

\section{Abstract}

The delivery of service quality by higher educational institutions will be become more prominent in the future for the success and sustainability of these institutions. The funding of South African universities by government is largely dependent on the attraction, retention and throughput of institutions. Therefore, it is imperative for management and academics to have an understanding of the perceptions and expectations of service quality of students, especially the academic performances at their institutions. The purpose of this study was to measure the perceptions and expectations of students with regard to a particular university in South Africa as to determine whether the university was meeting the service quality expectations of students. An adaptation of the SERVQUAL instrument was used to measure the perceptions and expectations of the students. A convenience sample was used to collect the data from students at three campuses of the institution. Service quality was measured by deducting the expectation scores from the perception scores $(S Q=P-E)$. Negative scores indicate that expectations exceed perceptions meaning that the organisation did not meet the expectations of customers with regard to service quality. Only two of the perceptions minus expectation question scores were positive, 21 of them were negative. This is indicative that the university is falling short in meeting the expectations of students. However, the scales were generic in nature and it should be interpreted with care and it is recommended that further in-depths focus group interviews should be conducted to measure the underlying nature of these shortcomings.

Keywords: Service quality, perceptions, expectations, servqual

\section{Introduction}

The landscape of tertiary educational institutions has changed dramatically, not only has the competition intensified locally among institutions to draw the best students, but so has competition increased from abroad. Funding has become another challenge for the future sustainability of local tertiary institutions. Two of the key factors that will determine whether a student will enrol at a particular university are the reputation of the university and whether it provides quality education. The purpose of this research study was to determine the students' perceptions whether the university delivers on its promise in providing quality services.

In a study by Wiese, van Heerden and Jordaan (2010) among first years at 6 institutions in South Africa it was found that quality of teaching was the most important factor for selecting an institution. Other more important factors identified were employment prospects, campus safety and academic facilities. Fees or costs did not feature under the ten most important factors. In an American study by Noel-Levitz, Inc (2012) it was found that cost, followed by financial aid and academic reputation were the three most important factors among first year students at public universities. In a study in Malaysia, academic programmes available, academic reputation of an institution and the marketability of the degree conferred were seen as the most important factors (Sidin, Hussin \& Soon, 2003). The scales used in the aforementioned studies were uni-dimensional where quality and reputation can also be measured using multi-dimensional scales (Parasuraman, Zeithaml \& Berry, 1988 \& Helm, 2001).

\section{Background and Literature Study}

As this was an exploratory research study it was decided to replicate the research study of Soutar, McNeil and Lim (1994) who examined the overseas students' perceptions of the service quality delivery by ten educational institutions in Western 
Australia. The research study of Soutar, et al. (1994) used the SERVQUAL questionnaire of Parasuraman, et al. (1988) and adapted it to suite an educational environment. The questionnaire of Soutar, et al. (1994) was further adapted for this particular research study regarding the South African university.

The SERVQUAL, a multiple-item scale for measuring consumer expectations and perceptions of service quality was developed and first published in 1988 (Parasuraman, et al.1988). The instrument had 22 expectation and 22 perception items (or questions) spread over five dimensions of; tangibles (four items), reliability (five items), responsiveness (four items), assurance (four items) and empathy (five items). Parasuraman, et al. (1988) described the five dimensions of quality as follows:

- Tangibles: Physical facilities, equipment, and appearance of personnel

- Reliability: Ability to perform the promised service dependably and accurately

- Responsiveness: Willingness to help customers and provide prompt service

- Assurance: Knowledge and courtesy of employees and their ability to inspire trust and confidence

- Empathy: Caring, individualised attention the firm provides its customers

The purpose of applying the SERVQUAL instrument is to determine the differences or gaps between service quality expectations and service quality perceptions, in other words, whether there are any service quality shortcomings, and on which particular service quality dimension item (Parasuraman, Zeithalm \& Berry, 1985 \& Parasuraman, et al. 1988). These gaps are measured as a difference score of $Q=P-E(P=$ Perceptions and $E=$ Expectations). This translates as the higher the difference score, the greater the shortfall of service quality delivery with regard to the expectations and perceptions of consumer or clients of a particular organisation.

The SERVQUAL measurement instrument is essentially a generic instrument which can be used for measuring service quality across a range of service organisations, in both the private and public sector (Parasuraman, et al. 1988; Firdaus, 2006 \& Ladhari, 2008). Being a generic instrument the SERVQUAL instrument has drawn a great deal of criticism with regard to, for example, the stability of the SERVQUAL scale, the ambiguity of the definition of consumer expectations and the dimensionality of the instrument, notwithstanding the fact that the instrument had been widely applied for research purposes (Ladhari, 2008). Furthermore, as the SERVQUAL scale consists of both expectation and perception questions, there is the debate whether the expectation questions are really necessary (Firdaus, 2006). Furthermore, Rowley (1996) states that there is still a continuing debate with regard to conceptual and methodological issues inferred by the statements below:

- That there are different formulations of service quality by different researchers making it difficult to standardise a measuring instrument for a particular area of study.

- Whether the applicability of a generic scale with a standard set of dimensions across different service sectors is possible? This is a questionable issue as many authors have raised the issue whether the service quality dimensions of Parasuraman et al. (1988) can only be classified into five dimensions (Robinson, 1999). Many other researchers have suggested different number of dimensions, for example, Carman (1990) has suggested ten dimensions, Cronin and Taylor (1992) have suggested only one dimension and, Babakus and Boller (1992) have suggested two dimensions.

- That there are still differences with regard to the relationship between service quality, customer satisfaction and purchasing behaviour. That the relevance of the data generated by a generic scale such as SERVQUAL to management with regard to the improvement of service quality is questioned.

Notwithstanding these arguments, the SERVQUAL instrument has been applied in many service sectors, for example, in higher education, banking, consulting and hospitality and many other sectors (Cuthbert,1996; Newman, 2001; Wilkens, Merrilees, \& Herington, 2007 \& Brochado, 2009). Given the background with regard to service quality the research questions of this study were the following:

- What are the expectation and perceptions of students regarding the service quality delivery at the university?

- What are the differences among the five dimensions of service quality such as tangibility, reliability, responsiveness, assurance and empathy?

\section{Research Design and Methodology}

\subsection{Sampling Design and Data Collection}

A convenience sample was used to draw the sample where undergraduate students of the university under study were asked to complete the questionnaire. The total sample consisted of 311 students. 


\subsection{Measuring Instrument}

This was a self-administered questionnaire. The questionnaire of this study included both the expectation and perception questions across the five dimensions of tangibles, reliability, responsiveness, assurance and empathy of service quality. The questionnaire was also submitted to a pilot test whether the students understood the questions.

There were 23 expectation and 24 perception questions. Appendix 1 provides an example of the perception questions. The $24^{\text {th }}$ question of the perception questions was to get an overall view of the service quality of the university. The scales used were seven point Likert scales. The questions on responsiveness and empathy were negatively phrased. Soutar, et al. (1994: 31) highlighted the reason for this as to avoid response bias. The responses to these questions had to be reversed in the analysis stage to guarantee for directional continuity. The questionnaire was completed by undergraduate students at the three campuses of the university under study.

\section{The Empirical Results}

\subsection{Reliability of scales}

Cronbach alpha was used to test the reliability of the scales for internal consistency and the coefficient should ideally be more than .70. Table 1 provides an overview of the reliability statistics of the overall expectation and perception scales. The overall perception question scales had the highest Cronbach alpha value of .897 and the lowest mean score of 4,292 (see Table 1). The group dimension scores also had high Cronbach alpha values. However, the Cronbach alpha value was the lowest of .526 for the empathy dimension indicating a low reliability of the scale (see Table 2).

Table 1: Reliability Statistics for the Overall Scales of the Student Sample

\begin{tabular}{|l|c|c|c|}
\hline Scale Type & Mean & Standard Deviation & Cronbach alpha \\
\hline Scale with expectation questions - 23 items & 5,751 & 1,8479 & .641 \\
\hline Scale with perception questions - 23 items & 4,292 & 1,8437 & .897 \\
\hline
\end{tabular}

Table 2: Grouped Mean Gap Scores and Standard Deviation of the Differences between the Grouped Dimensions of Perceptions and Expectations of the Student Sample

\begin{tabular}{|l|c|c|c|}
\hline Service Quality Dimensions & Mean Gap Scores & Standard Deviation & Cronbach alpha \\
\hline Tangibles & $-1,88$ & 2,13 & .798 \\
\hline Reliability & $-2,26$ & 2,14 & .838 \\
\hline Responsiveness & $-1,04$ & 2,75 & .656 \\
\hline Assurance & $-2,03$ & 2,00 & .788 \\
\hline Empathy &,- 299 & 3,00 & .526 \\
\hline
\end{tabular}

\subsection{Discussion of Students' responses}

The grouped mean gap scores of the student sample are provided in Table 2. The grouped mean gap scores have been calculated by taking the differences of all the question items under each dimension, for example, Questions one to five were taken together under the tangibility service quality dimension. These mean difference scores were obtained by deducting the grouped mean expectation scores from the grouped perception mean scores (P-E). All of them were negative indicating that the respondents (students) expected more with regard to the service quality delivery of the university. The grouped service quality dimension of empathy had a mean difference score of $-0,299$ between expectations and perceptions, meaning that the university was meeting the expectation of students more than the other service quality dimensions. The empathy dimension items generally deal with whether students are cared for and getting the necessary attention from the university. The grouped service quality dimension of reliability had the highest mean difference score of $-2,26$ between expectations and perceptions regarding service quality, an indication that the university did not perform well on the reliability service quality dimension.

The study of Soutar et al. (1994) also found that the reliability dimension had the highest difference score. A study among students by Pariseau and McDaniel (1997) found that assurance and reliability had a highly significant influence on the overall quality of services provided by an institution. Other studies could not find significant differences; a case in 
point is a study by Zafiropoulos and Vrana (2008). According to Wilson, Zeithaml, Bitner and Gremler (2012), the reliability dimension has been consistently shown as the most important determinant of perceptions of service quality. The reliability dimension items generally deal with the ability of an organisation to deliver on its promises. The grouped empathy service quality dimension scale in Table 2 had the highest standard deviation of 3,00 indicating that the views of students varied greatly with regard to their expectations and perceptions in respect of the service quality dimension. The standard deviations of the other grouped service quality dimensions were also high.

The individual tangibility dimension item results are provided in Table 3 (E1/P1 to E5/P5) and all of them had negative differences. The tangibility item E2/P2 had the highest perception minus expectation difference of -2,9357, meaning that the university is not doing well in addressing the needs of students in providing adequate facilities, as their expectations are greater than their perceptions with regard to satisfying this particular need. The individual dimension items of the reliability dimension all had high negative differences compared to all the other individual dimension items of the service quality study (see Table 3).

The individual dimension items of differences between the expectations of the assurance dimension were fairly the same, but yet indicating that there were some shortcomings with regard the assurance dimension of the service quality of the university. The empathy dimension was the only dimension that had positive differences between the individual dimensions items of E22/P22 and E23/P23. E22/P22 pertained to the issue of that the university does have the best interests of student at heart and E23/P23 was an indication that the university is open for long hours for the convenience of students. The $24^{\text {th }}$ question about the overall satisfaction of services quality delivery had a mean score of 4,6559 indicating a more positive perception of the service quality delivery.

Table 3: Perceptions minus Expectation Scores (P-E)

\begin{tabular}{|c|c|c|c|c|}
\hline \multirow{2}{*}{ Dimensions } & \multirow{2}{*}{ Legend } & Expectations & Perceptions & \multirow{2}{*}{ (P-E) } \\
\hline & & Average & Average & \\
\hline \multirow[t]{5}{*}{ Tangibility } & E1/P1 & 6,4887 & 4,4047 & $-2,0840$ \\
\hline & E2/P2 & 6,7717 & 3,8360 & -2.9357 \\
\hline & E3/P3 & 6,3151 & 4,5852 & $-1,7299$ \\
\hline & E4/P4 & 6,2026 & 4,9871 & $-1,2155$ \\
\hline & E5/P5 & 6,4309 & 4,9839 & $-1,4470$ \\
\hline \multirow{5}{*}{ Reliability } & E6/P6 & 6,6752 & 4,1736 & $-2,5016$ \\
\hline & E7/P7 & 6,6302 & 3,9582 & $-2,6720$ \\
\hline & E8/P8 & 6,1383 & 4,4116 & $-1,7267$ \\
\hline & E9/P9 & 6,6527 & 4,1833 & $-2,4694$ \\
\hline & E10/P10 & 6,6369 & 4,7106 & $-1,9263$ \\
\hline \multirow{4}{*}{ Responsiveness } & E11/P11 & 4,2926 & 4,0643 & $-0,2283$ \\
\hline & E12/P12 & 4,6881 & 3,9582 & $-0,7299$ \\
\hline & E13/P13 & 6,1158 & 4,2122 & $-1,9036$ \\
\hline & E14/P14 & 5,2733 & 3,9839 & $-1,2894$ \\
\hline \multirow{4}{*}{ Assurance } & E15/P15 & 6,2444 & 4,3859 & $-1,8585$ \\
\hline & E16/P16 & 6,5402 & 4,5627 & -1.9775 \\
\hline & E17/P17 & 6,6109 & 4,4244 & $-2,1865$ \\
\hline & E18/P18 & 6,3780 & 4,7299 & -1.6481 \\
\hline \multirow{5}{*}{ Empathy } & E19/P19 & 5,1286 & 4,0547 & $-1,0739$ \\
\hline & E20/P20 & 5,1672 & 3,6720 & $-1,4952$ \\
\hline & E21/P21 & 5,0707 & 3,6720 & $-1,3987$ \\
\hline & E22/P22 & 2,6559 & 4,3183 & 1,6624 \\
\hline & E23/P23 & 3,3473 & 4,1576 & 0,8103 \\
\hline
\end{tabular}

\section{Limitations of the Study}

The questionnaire addressed the service quality dimensions of the university as a whole and no distinction was made whether the problems that were identified related to either the academic or administration service quality delivery. A student could either have had bad experiences with an academic or administrative staff member and this could have influenced the overall responses of a particular student. The study only investigated the expectations and perceptions of undergraduate commerce students of the university, therefore, these findings cannot be generalised to other faculties 
such as engineering and medicine, for example, the teaching practices and academic support may be quite different.

Furthermore, only second-year students were included in the study and the expectation and perceptions of other undergraduate level and postgraduate were not part of the sample and again these findings cannot be generalised to all other students. There are no existing benchmarks of service delivery at other tertiary institutions to make a more informed comparison whether the service delivery is better or worse compared to other institutions. As the questionnaire questions were very generic in nature further research such as focus groups should be considered as to what are the specific shortcomings under each dimension item. This was a once off study and a longitudinal study should be considered as to determine whether the services of the university are improving or deteriorating over time.

\section{Conclusion}

The objective of the research study was to determine the service quality of a university in South Africa, furthermore, to determine whether there were any shortcomings in the delivery of services to students or whether there were any particular areas where the service delivery of the university exceeded the expectations of students. Of the 23 expectation and perception questions posed, 21 of them had negative differences where the expectation scores exceeded the perception scores. Only 2 expectation and perception questions had positive scores. These findings underscore the issue that the university is not meeting the expectations of the students. Given the overall results of the study, further in-depth studies would be recommended to improve on the service quality delivery of the university.

\section{References}

Babakus, E. \& Boller, G.W. (1992). An empirical assessment of the SERVQUAL scale. Journal of Business Research, 24,3: 253-68.

Brochado, A. (2009). Comparing alternative instruments to measure service quality in higher education. Quality Assurance in Education, 17, 2: 74-190.

Carman, J. (1990). Consumer Perceptions of Service Quality: An Assessment of the SERVQUAL Dimensions. Journal of Retailing, 66,1: 33-55.

Cronin, J. \& Taylor, S (1992). Measuring Service Quality: A Reeaxamination and Extension. Journal of Marketing, 56,3: 55-68.

Cuthbert, P. (1996). Managing service quality in HE: is SERVQUAL the answer? Managing Service Quality, 6,2: 11-16.

Firdaus, A. (2006). Measuring service quality in higher education: three instruments compared. International Journal of Research \& Methods of Education 29,1: 71-89.

Helm, S. (2001). An Introduction to a Complex Construct. (In: Helm, S., Liehr-Gobbers, K. \& Storck, C. Eds. Reputation Management). [Online] Springer. Berlin Heidelberg: 978-3-642-19266-1.

Ladhari, R. (2008). Alternative measures of service quality: a review. Managing Service Quality, 18,1: 65-86.

Newman, K. (2001). Interrogating SERVQUAL: a critical assessment of service quality measurement in a high street retail bank. International Journal of Bank Marketing, 19,3:126-139).

Noel-Levitz, Inc. (2002). National Research Report: Why Did They Enrol? The factors Influencing College Choice.

Parasuraman, A., Zeithaml. V. \& Berry, L. (1985). A Conceptual Model of Service Quality and its Implications for Future Research. Journal of Marketing, 49,4: 41-50

Parasuraman, A., Zeithaml, V. \& Berry, L. (1988). SERVQUAL: A Multi-Item Scale for Measuring Consumer Perceptions of Service Quality. Journal of Retailing, 64,1:12-40.

Pariseau, S. \& McDaniel, L. (1997). Assessing service quality in schools of business. International Journal of Quality \& Reliability Management, 14,3: 204-218.

Robinson, S. (1999). Measuring service quality: current thinking and future requirements. Marketing Intelligence \& Planning, 17,1: 21-32.

Rowley, J. (1996). Measuring Quality in Higher Education. Quality in Higher Education, 2,3: 237-255.

Sidin, S., Hussin, S. \& Soon, T. (2003). An exploratory Study of Factors Influencing the College Choice Decision of Undergraduate Students in Malaysia. Asia Pacific Management Review, 8,3: 259-280.

Soutar, G., McNeil, M. \& Kwee, L. (1994). Service Quality and the Overseas' student: Some Australian Experiences. Journal of Marketing and Logistics, 18,1/2: 28-40.

Wiese, M., van Heerden, C. \& Jordaan, Y. (2010). The Role of Demographics in Students' Selection of Higher Education Institutions. Acta Commercii, 10: 150-163.

Wilkens H., Merrilees, B., \& Herington, C. (2007). Towards an understanding of total service quality in hotels. Hospitality Management, 26(4): 840-853.

Wilson, A., Zeithaml, V., Bitner, M. \& Gremler, D. (2012). Services Marketing Integrating Customer Focus Across the Firm. $2^{\text {nd }}$ European Ed. Boston: McGraw-Hill. 


\section{Appendix 1}

\section{Perception Questions}

\begin{tabular}{|c|c|c|c|c|c|c|c|c|}
\hline P1 & My campus has modern equipment. & 1 & 2 & 3 & 4 & 5 & 6 & 7 \\
\hline $\mathrm{P} 2$ & My campus has enough facilities for all their students. & 1 & 2 & 3 & 4 & 5 & 6 & 7 \\
\hline P3 & The buildings and surroundings of my campus look attractive. & 1 & 2 & 3 & 4 & 5 & 6 & 7 \\
\hline P4 & The employees are of my campus are well dressed and appear neat. & 1 & 2 & 3 & 4 & 5 & 6 & 7 \\
\hline P5 & The buildings and surroundings of my campus are appropriate for the type of services provided. & 1 & 2 & 3 & 4 & 5 & 6 & 7 \\
\hline P6 & When my campus promises to do something by a certain time, it does so. & 1 & 2 & 3 & 4 & 5 & 6 & 7 \\
\hline P7 & When I have problems, my campus is understanding and helpful. & 1 & 2 & 3 & 4 & 5 & 6 & 7 \\
\hline P8 & My campus is dependable. & 1 & 2 & 3 & 4 & 5 & 6 & 7 \\
\hline P9 & My campus provides its services at the time it promises to do so. & 1 & 2 & 3 & 4 & 5 & 6 & 7 \\
\hline P10 & My campus keeps its records accurately. & 1 & 2 & 3 & 4 & 5 & 6 & 7 \\
\hline P11 & My campus does not tell students exactly when services will be performed. & 1 & 2 & 3 & 4 & 5 & 6 & 7 \\
\hline P12 & I do not receive service immediately from staff of my campus. & 1 & 2 & 3 & 4 & 5 & 6 & 7 \\
\hline P13 & The staff members from my campus are not always willing to help students. & 1 & 2 & 3 & 4 & 5 & 6 & 7 \\
\hline P14 & The staff members from my campus are too busy to respond to student requests immediately. & 1 & 2 & 3 & 4 & 5 & 6 & 7 \\
\hline P15 & I can trust the staff of my campus. & 1 & 2 & 3 & 4 & 5 & 6 & 7 \\
\hline P16 & I feel safe in my dealings with the staff of my campus staff. & 1 & 2 & 3 & 4 & 5 & 6 & 7 \\
\hline P17 & The staff members from my campus are polite. & 1 & 2 & 3 & 4 & 5 & 6 & 7 \\
\hline P18 & The staff members get enough support from my campus to do their job well. & 1 & 2 & 3 & 4 & 5 & 6 & 7 \\
\hline P19 & My campus does not give me individual attention. & 1 & 2 & 3 & 4 & 5 & 6 & 7 \\
\hline P20 & The staff members from my campus do not give me personal attention. & 1 & 2 & 3 & 4 & 5 & 6 & 7 \\
\hline P21 & The staff members from my campus do not know what my needs are. & 1 & 2 & 3 & 4 & 5 & 6 & 7 \\
\hline P22 & My campus does not have my best interests in mind. & 1 & 2 & 3 & 4 & 5 & 6 & 7 \\
\hline P23 & My campus does not open for long hours for the convenience of all their students. & 1 & 2 & 3 & 4 & 5 & 6 & 7 \\
\hline P24 & Overall, I am very satisfied with the services provided by my campus. & 1 & 2 & 3 & 4 & 5 & 6 & 7 \\
\hline
\end{tabular}

